\title{
Management of pepper verticillium wilt by combinations of inducer chemicals for plant resistance, bacterial bioagents and compost
}

\begin{abstract}
Inducer resistance chemicals (IRCs) Bion (BTH), chitosan and salicylic acid, bacterial bioagents, i.e. Bacillus chitinosporus, B. megaterium, B. pumilus, B. subtilis, B. thuringiensis, Pseudomonas fluorescens and P. putida and compost tea caused a reduction to the linear growth of the fungus Verticillium dahliae, in culture plates. In general, $P$. fluorescens followed by $B$. subtilis were the most efficient in reducing the linear growth of $V$. dahliae. The viability of microsclerotia of $V$. dahliae was greatly reduced by the tested bacterial bioagents. In addition, B. megaterium, B. subtilis, P. fluorescens and P. putida were the most efficient bioagents, where no microsclerotia germinated three weeks after treatment with these bioagents. In addition, few of microsclerotia germinated when treated with $B$. chitinosporus, B. pumilus and B. thuringiensis. However, all the microsclerotia of the control treatment were viable even three weeks after treatment with bioagents.

The combination and use singly of BTH, B. subtilis, P. fluorescens and compost resulted in a reduction of verticillium wilt in pepper and increase of fruit, photosynthetic pigments, and vitamin-C compared with the control treatment (infested with the causal fungus). Compost was the most efficient of single tactics in disease management. Moreover, no apparent infection was detected when BTH, the two bioagents B. subtilis and P. fluorescens and compost were used together and the fruit yield, photosynthesis pigments and vitamin- $\mathrm{C}$ were, similar to the control treatment (un-infested soil). Photosynthesis pigments including chlorophyll a, chlorophyll b and carotenoids as well as free and total ascorbic acid (vitamin-C) were greatly increased due to the tested treatments, i.e. BTH, both bioagents and compost in pepper plants grown in infested soil compared with those of untreated plants (grown in infested soil only). Compost was the best single treatment for minimizing the reduction in photosynthesis pigments in plants grown in infested soil with $V$. dahliae, as well as free and total ascorbic acid compared with plants grown in soil infested with the causal fungus without any another treatment.
\end{abstract}

Keywords: pepper, bacterial bioagents, compost, inducer resistance chemicals, fruit yield, management, photosynthesis pigments, vitamin-C, verticillium wilt
Volume 5 Issue 2 - 2018

\author{
Khairy Abdel-Maksoud Abada, Amany M F \\ Attia, Marwa Abdel-Latif Zyton \\ Department of Plant Pathology, Cairo University, Egypt
}

Correspondence: Khairy Abdel-Maksoud Abada, Department of Plant Pathology, Agriculture faculty , Cairo University, Giza, Egypt, Email dr_khairy_abada@yahoo.com

Received: February 10, 2018 | Published: April II, 2018
Abbreviations: IRCs, inducer resistance chemicals; BTH, benzothiadiazole; TAA, total ascorbic acid; DAA, dehydro-ascorbic acid; LSD, least significant differences; IPM, integrated pest management; DAPB, diacetyl-phloroglucinole; BCAs, biological control agents; SAR, systemic acquired resistance; SA, salicylic acid; PR, pathogenesis-related; ISR, induced systemic resistance; JA, jasmonic acid

\section{Introduction}

Pepper (Capsicum annum L.) is considered one of the most important vegetable crops in Egypt for local consumption and exportation. The economic importance of pepper cultivation in the world can be explained by its high nutritional value of antioxidants, vitamins and some other compounds. Therefore, improving the production of this crop is one of the objectives in agriculture in many countries. ${ }^{1}$ Many complaints have been received from pepper growers due to wilt and death of plants due verticillium wilt, caused by Verticillium albo-atrum and $V$. dahliae, especially when planted following tomato, potato or strawberry. The causal fungi are widespread in pepper plantations in Egypt. These pathogens are soil-borne and infect plants through the roots. ${ }^{2}$ They invade the plant's vascular system and prevent transport of water and nutrients. These fungi can infect about 300 species of host plants, including fruit plants, vegetables, forest trees, shrubs and flowers, as well as many weeds and some field crops. The fungus $V$. dahliae can survive in soil as microsclerotia, which are produced on the dying tissues of the host plant. Microsclerotia can also survive over a wide range of soil moisture and temperature conditions.

The infected plants show yellowing, chlorosis and necrosis of the lower leaves and premature defoliation. Vascular tissues of basal stem and tap roots have a brownish streak. The losses due to verticillium wilt can reach more than $80 \%$ under favorable wet and warm conditions. ${ }^{3}$ Soil biology is directly linked to agricultural sustainability as it is the driving force behind decomposition processes that break down complex organic molecules and substances and convert them into plant available forms. Soil microbial communities are important for sustaining the productivity of soils under sustainable and organic farming systems. To accomplish such systems, farmers adopt strategies such as crop rotation, cover cropping, and application of organic amendments (manures and composts) that increase soil organic matter and improve soil biology and quality.

Due to the hazardous effect of agrochemicals on human health, 
the demand for organic products is increasing since more consumers feel that they are healthier than those conventionally grown. Organic food consumption is part of a way of life and is associated with a strong interest in nature, society and the environment. One of the core philosophies of organic production systems is the development of healthy and productive soil that provides essential nutrients for plant growth, supports diverse and active soil biotic communities and balances the entire farm ecosystem. ${ }^{4,5}$ So, there is a growing demand for organic products. Management of verticillium wilt is currently accomplished through the use of soil fumigation by methyl bromide, use of fungicides and with partially resistant or tolerant cultivars. However, the application of soil fumigation and fungicides lead to ozone depletion, off-target pollution and create imbalance in the microbial community. These products can be unfavorable to the activity of beneficial organisms and may lead to development of resistance strains of the pathogens. ${ }^{6}$

Biological control is a safer and ecologically acceptable alternative to chemical control in the management of many soil-borne diseases. ${ }^{4,5,78}$ Biological control of verticillium wilt of pepper can be achieved by promoting the native antagonists, or introducing alien antagonists that are found in compost. Bacillus and Pseudomonas have been found effective in inhibiting many soil-borne pathogens. ${ }^{4,5,7}$
The objective of this work is to investigate the role of IRCs, bacterial bioagents and compost (singly and in combination) on management of pepper verticillium wilt.

\section{Materials and methods}

\section{Isolation, purification and identification of the associated fungi to pepper wilt}

Pepper plants showing characteristic wilt symptoms (Figure 1) were collected from Behera, Ismailia, Sharkia, Menofia, Kalubia, Giza and Fayioum governorates, Egypt. The infected roots were thoroughly washed in running tap water and cut into small pieces with lesion having half healthy and half diseased tissue. The cut pieces were surface sterilized with $2 \%$ sodium hypochlorite for two minutes then subsequently washed in three changes of sterilized water to eliminate the sodium chlorite. The sterilized pieces were transferred onto PDA medium in Petri-dishes. Petri-dishes were incubated at $25 \pm 2^{\circ} \mathrm{C}$ and observed periodically for the fungal growth. The isolated fungi were purified by single spore technique or hyphal tip method and maintained on sterilized slips in slants throughout this investigation. The emerged fungi were identified on the basis of their morphological features and the description of (Figure 1). ${ }^{9-11}$

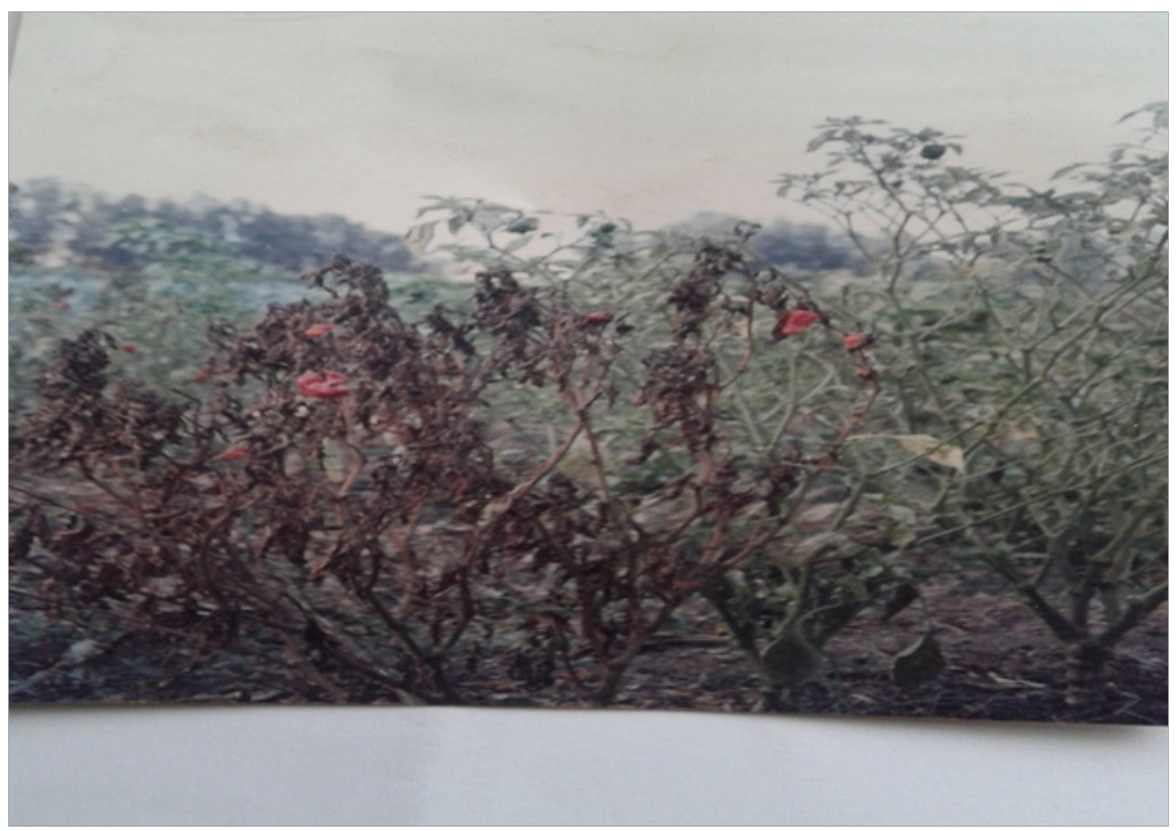

Figure I Pepper plants showing symptoms of verticillium wilt.

\section{Pathogenicity test}

Formalin disinfested clay soil was infested with $2 \%$ pathogen inoculum (grown on corn-sand medium for two weeks) of the seven isolates of V. albo-atrum and V. dahliae, each alone, and distributed in plastic pots $(25 \mathrm{~cm}$ in diameter). Marconi $\mathrm{cv}$. transplants were dipped in $1 \%$ of the fungicide tachigaren $30 \mathrm{SL}$ (Hymexazol) for 30 minutes (Summit Agro Comp) to make sure that the transplants were not infected with any fungal pathogens. Two plants were transplanted in each pot and five pots were used for each isolate which were arranged in a complete randomized block. Transplants in uninfested soil were used as controls. The severity of infection by both V. albo-atrum and $V$. dahliae was assessed three months after transplanting. Plant height and fresh weight of the foliage growth of the survived plants were measured three months after transplanting.

\section{Source of the antagonistic bacterial bioagents}

The seven antagonistic bacterial bioagents, i.e. Bacillus chitinosporus, B. megaterium, B. pumilus, B. subtilis, B. thuringiensis, $P$. fluorescens and $P$. putida (maintained on nutrient peptone agar medium) were previously isolated from eggplant rhizospheric soil. ${ }^{5}$ 
Effect of the tested IRCs, bioagents and compost on growth of $V$. dahliae in culture

\section{Effect of the IRCs}

The effect of the antioxidants Bion (Benzothiadiazole; BTH), chitosan (cellulose with the hydroxyl at position $\mathrm{C}_{2}$ substituted with an acetamido group) and salicylic acid (monohydroxybenzoic acid) on the on the linear growth of the tested pathogen was carried out in vitro. The concentrations of $0.0,5,10,20$ and $40 \mathrm{mM}$ were prepared depending on their molecular weight.

The prepared concentrations were sterilized using $0.25 \mu \mathrm{m}$ syringe filter. Each concentration was mixed with the calculated amount of sterilized PDA medium $\left(\right.$ at $\left.45^{\circ} \mathrm{C}\right), \mathrm{n}$ and poured into the Petri-dishes $(20 \mathrm{ml} /$ plate). The medium+IRC were inoculated with $5 \mathrm{~mm}$ discs of the test pathogen taken from seven day old cultures. PDA plates inoculated with the test pathogen, but not amended with the IRCs were maintained as controls. Plates were then incubated at $25 \pm 1{ }^{\circ} \mathrm{C}$. Five replications were prepared for each treatment. The linear growth was measured when the plates of the control treatment were covered with the fungal mycelia. Inhibition percentage of mycelial growth of the tested pathogen was calculated by the formula:

$$
I=(C-T) / C X 100
$$

Where;

$$
\begin{aligned}
& \mathrm{I}=\text { Percent of inhibition in growth of the tested pathogen } \\
& \mathrm{C}=\text { Linear growth of the pathogen }(\mathrm{mm}) \text { in control } \\
& \mathrm{T}=\text { Linear growth of the pathogen }(\mathrm{mm}) \text { in treatment }
\end{aligned}
$$

\section{Effect of the antagonistic bacteria}

The effect of the culture filtrate for isolates of Bacillus megaterium, B. pumilus, B. subtilis, Pseudomonas fluorescens and P.putida on the linear growth of $V$. dahliae was tested using the method by Dennis et al. ${ }^{12}$ One hundred ml. of nutrient peptone medium were put in 250 $\mathrm{ml}$ flasks and sterilized by steamer for three successive days. The medium was inoculated with a loop-full of the desired bioagent taken from a two day-old culture. Inoculated flasks were incubated on a rotary shaker at $200 \mathrm{rpm}$ for 2 days at $25 \pm 1^{\circ} \mathrm{C}$. The culture filtrate was sterilized using a $0.25 \mu \mathrm{m}$ syringe filter. The culture filtrate of the bioagent was mixed with PDA medium in different proportion $(0.0,20$, 50 and $75 \%)$ and poured into Petri-dishes $(20 \mathrm{ml} /$ plate). The medium was inoculated with $5 \mathrm{~mm}$ discs of the test pathogen, taken from a seven day old culture. PDA plates inoculated with the test pathogen, but not amended with the culture filtrate of the tested bioagents were maintained as controls. Plates were then incubated at $25 \pm 1^{\circ} \mathrm{C}$. Five replications were maintained for each treatment. The linear growth was measured when the plates of the control treatment were covered with the fungal mycelia. Inhibition percentage of the mycelial growth of the test pathogen was calculated as mentioned before.

\section{Effect of compost tea}

One kg of plant compost (Bio-Pianta, Al-Menofia Fertilizers and Chemical Company; pH 7.2, EC 34, total nitrogen (\%) 1.3 and $\mathrm{C} / \mathrm{N}$ ratio 18:1) was soaked overnight in 3-liter water and filtered through two layers of Whitman 1 filter paper. Measured amounts of potato broth, dextrose and agar were added to $20,40,60,80$ and $100 \%$ of the filtrate and steamed for three successive days then poured in sterilized Petri-dishes. The medium was inoculated with $5 \mathrm{~mm}$ discs of the test pathogen cut from a five-day old culture. PDA plates inoculated with the test pathogen, but not amended with compost filtrate (normal PDA) were maintained as controls. Plates were then incubated at $25 \pm 1^{\circ} \mathrm{C}$. Five replications were maintained for each treatment. Inhibition percentage of the mycelial growth of test pathogens was calculated as mentioned before.

\section{Effect of the antagonistic bacteria on the viability of microsclerotia of V. dahliae}

Pepper plants grown in soil infested with $V$. dahliae for three months were removed and a longitudinal section was cut from each plant, stored in paper bags, and air dried in the laboratory for one month to produce microsclerotia. The plants were shaken and/or crushed by scalpel on Petri-dishes to collect the microsclerotia. One $\mathrm{ml}\left(1 \times 10^{10} \mathrm{cfu} / \mathrm{ml}\right.$. water $)$ of any of the seven tested bioagents (2 days old), i.e. Bacillus chitinosporus, B. megaterium, B. pumilus, $B$. subtilis, $B$. thuringiensis, $P$. fluorescens and $P$. putida were added to each Petri-dish containing the microsclerotia of $V$. dahliae, shaken well and air dried for four hours and incubated at $25 \pm 2{ }^{\circ} \mathrm{C}$. Petridishes without any additions (sterilized water only) were prepared as controls. The roots of three months old pepper plants (two plants) were washed thoroughly with tap water then distilled water then placed in conical flasks (four plants $/ 250 \mathrm{ml}$ flask) containing distilled water $(100 \mathrm{ml})$ for one week to obtain the root exudates. One $\mathrm{ml}$ of root exudates was added to each plate containing microsclerotia (100 sclerotia) plus the biocontrol agent. These plates were sealed with para-film then incubated in darkness at $25 \pm 1^{\circ} \mathrm{C}$ for one, two and three weeks (three dishes for each incubation period for each bioagent and the control.) One $\mathrm{ml}$ from lacto-phenol cotton blue stain was added to each Petri-dish containing any treatment at the time of examination for microsclerotial germination to kill and fix the germinated microsclerotia. At each incubation period, 100 microsclerotia were examined for germination in each treatment and each time period. The germinated (grown) microsclerotia were examined by the microscope $(10 \mathrm{X})$, counted and the number of the germinated microsclerotia of each treatment was recorded.

\section{Effect of the combination of IRC BTH, B. subtilis and $P$. fluorescens and compost on management of verticillium wilt and pepper fruit yield}

Transplants of the pepper cultivar Marconi were used for this experiment. The plots $(1 \times 1 \mathrm{~m})$ were infested with $2 \%$ inoculum (grown on sterilized corn-sand medium in $500 \mathrm{ml}$ glass bottles) of the tested pathogen. The plots were divided into the following treatments:

i.Pepper transplants grown in foam trays were irrigated with Bion (BTH) at $40 \mathrm{mM}$ twice with a five days interval before transplanting in plots infested with the causal pathogen (three plots)

ii. Three infested plots with the causal pathogen received $2 \mathrm{~kg}$ compost for each plot (mixed thoroughly with the soil), two weeks before transplanting pepper

iii. Three infested plots with the causal pathogen were infested with B. subtilis $\left(1 \times 10^{6} \mathrm{cfu} / \mathrm{L}\right.$ water $)$ at the rate of $2 \mathrm{~L} / \mathrm{plot}$, two weeks before transplanting pepper

iv. Three infested plots with the causal pathogen were infested with P. fluorescens $\left(1 \times 10^{6} \mathrm{cfu} / \mathrm{L}\right.$ water $)$ at the rate of $2 \mathrm{~L} / \mathrm{plot}$, two weeks before transplanting pepper 
v. A combination of treatments 1 and 2 were utilized (BTH irrigated on seedlings; compost added to soil)

vi. A combination of treatments 1 and 3 (BTH irrigated on seedlings; B. subtilis added to soil)

vii. A combination of treatments 1 and 4 (BTH irrigated on seedlings; P. fluorescens added to soil)

viii. A combination of treatments 2 and 3

ix. A combination of treatments 2 and 4

$\mathrm{x}$. A combination of treatments 3 and 4

xi. A combination of treatments 1,2 , and 4

xii. Infested plots with the causal pathogen were left without another treatment

xiii. Un-infested plots with any pathogen were left without another treatment

The plots, in complete randomized block, were then irrigated and left for three days and then transplanted with plants that had been dipped in $1 \%$ of the fungicide tachigaren for 30 minutes just before transplanting to kill any fungal pathogens that may have been present Sixteen transplants were placed in each plot and three plots were used for each treatment. The plots were irrigated when it was necessary and fertilized with the recommended doses as recommended by Min. of Agric. and Land Reclamation. Disease severity was assessed on random plants in each plot six months after transplanting and the average was recorded. Mature fruits were harvested periodically, counted and weighed.

\section{Disease assessment}

Pepper plants were monitored for disease symptoms periodically until the end of the experiment (each month). Disease severity on aboveground plant parts was evaluated using a scale (0-5) modified by Bejarano-Alcazar et al. ${ }^{13}$ based on the percentage of foliage affected with chlorosis, necrosis, wilting, defoliation as follows:

Where,

$0=$ No foliar symptoms

$1=$ Chlorosis and/or wilt restricted to the first leaf

$2=$ Chlorosis and/or wilt extending beyond the first leaf

3 = Moderate to severe foliar symptoms usually with some abscised leaves

$4=$ Severe foliar symptoms on the entire plant, and

$5=$ Dead plant

Disease severity on foliage growth $\%=\sum(n x v) / 5 N X 100$

Where,

$\mathrm{n}=$ Number of wilted leaves in each category

$\mathrm{v}=$ Numerical values of each category

$\mathrm{N}=$ Total number of the wilted leaves

The plants were also rated for vascular discoloration by the causal fungus using the devised scale (0-5) by Sanogo et al. ${ }^{14}$ using the following formula:

Where,

$0=$ No discoloration

$1=$ Light discoloration evident as spotty areas in the longitudinalsection of the basal stem and upper part of the root

$2=$ More continuous discoloration covering an area between one quarter and one half of the basal stem and upper part of the root, but light in color

3 = Vascular discoloration (moderate in color) evident in a band encircling almost the entire of the basal stem and upper part of the root

4 = Vascular discoloration darker in color than in 1 or 2 , and evident across most of the vascular tissue in a the basal stem and upper part of the root, and

$5=$ Plant severely damaged, vascular discoloration evident throughout the basal stem and upper part of the root

Disease severity on the vascular $\%=\sum(n x v) / 5 N X 100$

Where,

$\mathrm{n}=$ Number of infected vascular in each category

$\mathrm{v}=$ Numerical values of each category

$\mathrm{N}=$ Total number of the infected vascular

Plant height of the grown plants, and the average number of fruits / plant and weight of fruits / plant were measured.

\section{Estimation of photosynthetic pigments and ascorbic acid (vitamin-C)}

The photosynthetic pigments (chlorophyll a, chlorophyll b and carotenoids) were estimated spectrophotometrically according to Metzner et al. ${ }^{15}$ Ten gram fresh weight of pepper leaves, taken from five randomly plants, were homogenized in $85 \%$ aqueous acetone for $10 \mathrm{~min}$. The homogenized tissues were centrifuged (10.000 rpm for 10 minutes), and the supernatant was adjusted to $100 \mathrm{~mL}$ with $85 \%$ acetone and measured against a blank of pure $85 \%$ aqueous acetone at three wavelengths of 452.5, 644 and $663 \mathrm{~nm}$. Dilutions were used to determine the concentrations of the pigment fractions.

Both free (FAA) and total ascorbic acid (TAA) were estimated spectrophotometrically according to the procedure mentioned by Hodges et al. ${ }^{16}$ Fresh leaf tissues $(3 \mathrm{~g})$ were weighed and placed in a $50 \mathrm{~mL}$ centrifuge tube and $10 \mathrm{~mL}$ of ice-cold $5 \%(\mathrm{w} / \mathrm{v})$ metaphosphoric acid was added, followed by homogenization at the speed of 15,000 rpm for $1 \mathrm{~min}$ in an ice-water bath by use of a homogenizer. The homogenized tissues were centrifuged at $7000 \mathrm{rpm}$ for $15 \mathrm{~min}$ at $4^{\circ} \mathrm{C}$, and the supernatant was filtered through Whitman No. 4 filter paper. The filtrate was used for estimating FAA and TAA by converting dehydro-ascorbic acid (DAA) to FAA with dithiothreitol. Both FAA and TAA were estimated spectrophotometrically at $525 \mathrm{~nm}$. The concentrations of FAA and TAA were calculated by using the standard curve (all $\mathrm{R}^{2} \geq 0.99$ ) of $\mathrm{L}$-ascorbic acid and their difference was equal to the concentration of DAA. The content of chlorophyll a, chlorophyll b and carotenoids was calculated using the formula of Arnon: ${ }^{17}$ 
Chlorophyll a $(\mathrm{mg} / \mathrm{ml})=12.7 \triangle A 663-2.69 \Delta A 645$,

Chlorophyll $b(\mathrm{mg} / \mathrm{ml})=22.9 \Delta A 645-4.68 \Delta A 663$, and

Carotenoids $(\mathrm{mg} / \mathrm{ml})=4.75 \Delta A 452.5-0.226 C(a+b)$,

Where,

$\Delta \mathrm{A}$ is the absorbance at the respective wavelength.

\section{Statistical analysis}

Data were statistically analyzed using the standard procedures for complete randomized block and split design as mentioned by Snedecor et al. ${ }^{18}$ The averages were compared at the 5\% level using least significant differences (LSD) according to Fisher. ${ }^{19}$

\section{Results}

\section{Isolation, purification and identification of the} associated fungi to pepper wilt

Isolation procedures from pepper roots of plants showing characteristic symptoms of wilt collected from Behera, Ismailia, Sarkis, Menofiya, Kalubia, Giza and Fayoum governorates yielded 190 fungal isolates belonging to six genera. The isolated fungi were purified and identified as: Alternaria spp., Fusarium oxysporum, F. solani, Macrophomina phaseolina, Pythium ultimum, Rhizoctonia solani, Verticillium albo-atrum and $V$. dahliae. The fungus $F$. oxysporum had the highest occurrence and frequency, with 35 isolates for a frequency of $18.4 \%$, followed by $V$. dahliae (33 isolates and a $17.4 \%$ frequency), and Alternaria spp. (28 isolates and 14.7\% frequency). The least frequently isolated pathogens were $P$. ultimum (14 isolates and 7.4\% frequency), M. phaseolina (16 isolates and $8.4 \%$ frequency) and $R$. solani (17 isolates and $9.0 \%$ frequency). The occurrence of the isolated fungi from the six governorates was similar. The isolates of $V$. albo-atrum and $V$. dahliae were selected and tested for their pathogenicity to choose the most virulent one (Table 1).

\section{Pathogenicity test of the seven isolates of V. albo-atrum and V. dahliae}

All isolates were pathogenic to pepper (Table 2). Isolates of $V$. dahliae were more aggressive than isolates of $V$. albo-atrum. The isolate from Menofia governorate of $V$. albo-atrum was more aggressive than other isolates of the same species, with a wilt severity on foliage and the xylem of 22.2 and $24.8 \%$, respectively and with the shortest plant height $(30.9 \mathrm{~cm})$ and lowest foliage fresh weight $(117.6$ $\mathrm{g} / \mathrm{plant})$. An isolate from the Giza governorate of $V$. dahliae was the most aggressive from that species, with a wilt severity of 25.1 and $29.5 \%$ on foliage and the xylem, respectively and with the shortest plant height $(28.0 \mathrm{~cm})$ and lowest foliage fresh weight $(117.0 \mathrm{~g} / \mathrm{plant})$. Both fungal species isolated from Behera and Fayoum governorates resulted in the lowest wilt severity.

Table I Occurrence and frequency of fungi associated with pepper wilt of samples collected from seven Egyptian governorates during August 20 I 6

\begin{tabular}{|c|c|c|c|c|c|c|c|c|c|}
\hline \multirow{2}{*}{ Isolated fungi } & \multicolumn{9}{|c|}{ Occurrence of the isolated fungi at \% } \\
\hline & Behera & Sharkia & Ismailia & Menofia & Kalubia & Giza & Fayoum & Total & Frequency \\
\hline Alternaria spp. & 4 & 3 & 4 & 3 & 4 & 6 & 4 & 28 & 14.7 \\
\hline Fusarium oxysporum & 4 & 6 & 5 & 4 & 6 & 5 & 5 & 35 & 18.7 \\
\hline F. solani & 2 & 4 & 5 & 3 & 4 & 2 & 3 & 23 & 12.1 \\
\hline $\begin{array}{l}\text { Macrophomina } \\
\text { phaseolina }\end{array}$ & 3 & 3 & 2 & I & 2 & 3 & 2 & 16 & 8.4 \\
\hline Pythium ultimum & I & 2 & 2 & 3 & 3 & 2 & I & 14 & 7.4 \\
\hline Rhizoctonia solani & 3 & 4 & 3 & 3 & 4 & 3 & 4 & 24 & 12.6 \\
\hline Verticillium albo-atrum & 3 & 2 & 3 & 2 & 2 & 3 & 2 & 17 & 9 \\
\hline V. dahliae & 5 & 4 & 4 & 5 & 6 & 5 & 4 & 33 & 17.4 \\
\hline Total & 25 & 28 & 28 & 24 & 31 & 29 & 25 & 190 & ---- \\
\hline
\end{tabular}

Table 2 Pathogenicity test of the seven isolates of both Verticillium albo-atrum and V. dahliae using transplants of pepper plants (Marconi cv.), greenhouse experiment

\begin{tabular}{lllllllll}
\hline & \multicolumn{3}{l}{ \% Disease severity on } & & \multicolumn{2}{l}{ Plant } & \multicolumn{3}{c}{ Foliage fresh } \\
\hline \multirow{2}{*}{ Governorates } & Foliage & Growth & Xylem & Vascular & \multicolumn{2}{l}{ Height (cm) } & \multicolumn{2}{l}{ Weight (g) } \\
\cline { 2 - 10 } & VA* & VD** & VA & VD & VA & VD & VA & VD \\
\hline Behera & 16.6 & 20 & 20.1 & 23.8 & 37.6 & 32 & 127.2 & 123.8 \\
Ismailia & 19.7 & 22.8 & 22.9 & 27.3 & 35 & 29.8 & 122.4 & 118.2 \\
Sharkia & 19.1 & 22 & 22.1 & 26.1 & 35.2 & 29 & 123 & 119 \\
Menofia & 22.2 & 22.4 & 24.8 & 28 & 30.9 & 29.5 & 117.6 & 110 \\
Kalubia & 20.3 & 23.2 & 23.3 & 28.7 & 34.5 & 29 & 120.2 & 115.8 \\
Giza & 21.4 & 25.1 & 23.4 & 29.5 & 31.8 & 28 & 121 & 117 \\
Fayoum & 18.4 & 20 & 20.3 & 25 & 36 & 31.4 & 125 & 122 \\
Control & 0 & 0 & 0 & 0 & 42.9 & 42.9 & 165.8 & 165.8 \\
L.S.D. at 5\% & 2.3 & 2.1 & 2.1 & 2.2 & 2.5 & 2.4 & 4.8 & 4.6 \\
\hline
\end{tabular}

$*=$ V.albo-atrum,$* *=$ V. dahlia 
The severity of verticillum wilt was negatively correlated with plant height and foliage fresh weight. No apparent symptoms of wilt were observed on the control plants which also had the tallest plants $(42.9 \mathrm{~cm})$ and the highest foliage fresh weight $(165.8 \mathrm{~g})$. V. alboatrum and $V$. dahliae were successfully reisolated from the diseased plants, completing Koch's postulates.

Effect of the tested IRCs, bioagents and compost on the growth of V. dahliae in vitro

\section{Effect of the IRCs}

Bion (BTH), chitosan and salicylic acid resulted in significant reductions to the linear growth of $V$. dahliae compared with the control treatment (Table 3). The inhibitory effect to the linear growth increased with increasing IRCs concentration. BTH was the most effective chemical at reducing fungal growth at all tested concentrations, and completely inhibited growth at $20 \mathrm{mM}$.

\section{Effect of the bioagents}

The culture filtrate from the bioagents (Table 4) resulted in a significant reduction to the linear growth of $V$. dahliae compared with the control treatment. This reduction increased with increasing concentration. P. fluorescens caused the highest inhibitory effect to $V$. dahliae followed by B. subtilis, with an average growth of 45.8 and $46.8 \mathrm{~mm}$, respectively (Table 4). B. chitinosporus followed by $B$. pumilus was the least effective at reducing growth of $V$. dahliae with an average growth of 57.1 and $55.9 \mathrm{~mm}$, respectively. The other bacteria resulted in intermediate control.

Table 3 Effect of three ICRs on linear growth $(\mathrm{mm})$ of Verticillium dahliae, 9 days after inoculation at $25 \pm 1^{\circ} \mathrm{C}$

\begin{tabular}{lllllll}
\hline IRCs & \multicolumn{4}{l}{ Average linear growth $(\mathbf{m m}) *$ at IRC concentration $(\mathbf{m M})$} & Mean \\
\hline Bion & 90 & 82.2 & 50.8 & 0 & 0 & 44.6 \\
Chitosan & 90 & 85.4 & 586.6 & 14.4 & 10 & 48.4 \\
Salicylic acid & 90 & 86.6 & 55.8 & 17.4 & 13 & 50 \\
Mean & 90 & 84.7 & 53.7 & 19.1 & 7.7 & --- \\
\hline
\end{tabular}

LS.D. at $5 \%$ for:

IRCs $(I)=2.5$, Concentrations $(C)=2.9$ and $I \times C=3 . I$.

Table 4 Effect of Bacillus spp. and Pseudomonas spp. culture filtrate on the linear growth of Verticillium dahliae, 9 days after inoculation at $25 \pm I^{\circ} \mathrm{C}$.

\begin{tabular}{lccccc}
\hline \multicolumn{6}{c}{ Linear growth (mm) at concentration of culture filtrate (\%) } \\
\hline Bioagents & $\mathbf{0}$ & $\mathbf{2 5}$ & $\mathbf{5 0}$ & $\mathbf{7 5}$ & Mean \\
\hline B. chitinosporus & 90 & 79 & $4 I$ & 18.4 & 57.1 \\
B. megaterium & 90 & 73.4 & 34.2 & 10.2 & 52 \\
B. pumilus & 90 & 78.6 & 38 & 16.8 & 55.9 \\
B. subtilis & 90 & 66.2 & 30.8 & 0 & 46.8 \\
B. thuringiensis & 90 & 75.8 & 37.2 & 16.4 & 54.9 \\
P. fluorescens & 90 & 64.2 & 28.8 & 0 & 45.8 \\
P. putida & 90 & 68.6 & 33 & 14.6 & 51.6 \\
Mean & 90 & 72.2 & 34.7 & 8.8 & ------ \\
\hline
\end{tabular}

L.S.D. at $5 \%$ for:

Bioagents $B=2.0$, Conc. $(C)=2.3$ and $B \times C=3.2$

\section{Effect of compost tea}

Compost tea resulted in a significant reduction to the linear growth of $V$. dahliae compared with the control treatment (Table 5). This reduction increased with increasing concentration of compost tea. In addition, the causal fungus failed to grow at the concentration of $75 \%$.

Table 5 Effect of compost tea on the linear growth of Verticillium dahliae, 9 days after incubation at $25 \pm 1^{\circ} \mathrm{C}$.

\begin{tabular}{ll}
\hline Concentrations $(\%)$ & Average linear growth $(\mathbf{m m})$ \\
\hline 25 & 72.6 \\
50 & 36.6 \\
65 & 0 \\
0 & 90 \\
L.S.D. at $5 \%$ & 2.7 \\
\hline
\end{tabular}

\section{Effect of bacterial bioagents on the viability of $V$. dahliae microsclerotia}

The viability of microsclerotia was greatly reduced by the bacterial bioagents (Table 6). B. megaterium, B. subtilis, P. fluorescens and $P$. putida were the most efficient bioagents, where no microsclerotia germinated three weeks after the treatment with these bioagents. In addition, few microsclerotia germinated due to the treatments with $B$. chitinosporus, B. pumilus and B. thuringiensis. All the microsclerotia in the control treatment were still viable after three weeks.

Effect of the combination of BTH, the bioagents $B$. subtilis and $P$. fluorescens and compost on management of pepper verticillium wilt and fruit yield

The IRC Bion (BTH), the bioagents B. subtilis and P. fluorescens and compost either singly or in combination, caused a significant 
reduction in verticillium wilt severity and discoloration of the xylem. Pepper plants also had a significant increase in the number of fruit and fruit weight in response to these treatments either singly or in combination (Table 7) compared to the $V$. dahliae infested control. Compost was the most efficient disease control treatment in this regard compared with the other three types of disease management, i.e. BTH and both bioagents when each of them was used alone. In addition, the values of wilt severity were higher on the foliage growth than those on the xylem vesicles. No apparent infection by $V$. dahliae was observed when the combination of BTH, both bioagents and compost was used and the produced fruit yield, were similar to the control treatment (uninfested soil). In addition, pepper plants grown in soil infested with the causal fungus had the highest disease severity and produced the lowest fruit yield (20.7 fruit and $0.465 \mathrm{~kg} / \mathrm{plot})$.

The severity of verticillium wilt on both foliage growth and xylem vesicles was reflected on the number of fruit and weight (yield).

Table 6 Effect of bacterial bioagents on the viability of Verticillium dahlia microsclerotia over time.

\begin{tabular}{llll}
\hline \multirow{2}{*}{ Bioagents } & \multicolumn{3}{l}{ Viability (\%) of microsclerotia } \\
over time (week) & \\
\hline & One & Two & Three \\
\hline Bacillus chitinosporus & 86 & 38 & 12 \\
B. megaterium & 74 & 32 & 0 \\
B. pumilus & 76 & 29 & 5 \\
B. subtilis & 63 & 22 & 0 \\
B. thuringiensis & 72 & 28 & 5 \\
Psuedomonas fluorescens & 60 & 17 & 0 \\
P. putida & 70 & 26 & 0 \\
Control & 100 & 100 & 100 \\
\hline
\end{tabular}

Table 7 Effect of the combination among the IRC BTH, the bioagents Bacillus subtilis and Pseudomonas fluorescens and compost on the management of pepper Verticillium wilt (Marconi cv.) as well as fruit yield, plot experiment

\begin{tabular}{|c|c|c|c|c|}
\hline \multirow{2}{*}{ Treatments } & \multicolumn{2}{|c|}{$\%$ Wilt severity on } & \multirow{2}{*}{ No. of fruits/Plant } & \multirow{2}{*}{$\begin{array}{l}\text { Weight fruits } \\
\text { (kg)/plant }\end{array}$} \\
\hline & Foliage growth & Xylem vesicles & & \\
\hline Bion (BTH) & 10,1 & 8.9 & 23.7 & 0.858 \\
\hline Compost (C) & 7.7 & 6.6 & 29.9 & 0.995 \\
\hline B.acillus subtilis (BS) & 9.2 & 7.3 & 25.2 & 0.97 \\
\hline Pseudomonas fluorescens (PF) & 9 & 7 & 32 & 0.985 \\
\hline $\mathrm{BTH}+\mathrm{C}$ & 5 & 3.2 & 36 & 1.19 \\
\hline$B T H+B S$ & 5.7 & 3.8 & 35 & 1.18 \\
\hline $\mathrm{BTH}+\mathrm{PF}$ & 5 & 3 & 38.2 & 1.2 \\
\hline $\mathrm{C}+\mathrm{BS}$ & 3 & 1.8 & 40 & 1.25 \\
\hline$C+P F$ & 2.5 & 1.4 & 40 & 1.25 \\
\hline $\mathrm{BS}+\mathrm{PF}$ & 3.8 & 2.1 & 39 & 1.17 \\
\hline $\mathrm{BTH}+\mathrm{C}+\mathrm{BS}+\mathrm{PF}$ & 0 & 0 & 44.6 & 1.32 \\
\hline Control (Infested soil) & 23.9 & 35.9 & 20.7 & 0.465 \\
\hline Control (Un-infested soil) & 0 & 0 & 46.4 & 1.38 \\
\hline L.S.D. at $5 \%$ & 2.9 & 3.1 & 4.2 & 0.132 \\
\hline
\end{tabular}

\section{Estimation of Photosynthesis Pigments and Ascorbic} Acid

The contents of the photosynthesis pigments and free and total ascorbic acid were elevated in the tested treatments compared with the infested control (Table 8). Compost had the highest concentration of photosynthetic pigments and ascorbic acid for plants infected with
V. dahliae (ranging from 40 to $64 \%$ higher than the infested control), while Bion had the lowest concentration of photosynthetic pigments and total ascorbic acid among control treatments (ranging from 29 to $55 \%$ above the infested control). The infested control had a reduction in photosynthetic pigments ranging from 28 to $42 \%$ compared to the uninfested control, and a reduction in ascorbic acid ranging from 39 to $43 \%$ (Table 8 ).

Table 8 Effect of Bion, bioagents and compost on the photosynthesis pigments (chlorophyll a, chlorophyll b and carotenoids) and total ascorbic acid of pepper plants infected with Verticillium dahliae.

\begin{tabular}{llllll}
\hline \multirow{2}{*}{ Treatment } & \multicolumn{2}{l}{ Photosynthesis pigments* } & \multicolumn{2}{l}{ Ascorbic acid** } \\
\cline { 2 - 6 } & Chlorophyll -a & Chlorophyll -b & Carotenoids & Free & Total \\
\hline Bion & 1.45 & 1.15 & 0.85 & 32.2 & 45.7 \\
Bacillus subtilis & 1.52 & 1.18 & 0.87 & 31.7 & 46.9 \\
Pseudomonas fluorescens & 1.53 & 1.2 & 0.88 & 32 & 47.3 \\
Compost & 1.6 & 1.25 & 0.9 & 33.1 & 49.2 \\
Control (Infested soil) & 1 & 0.89 & 0.55 & 21.7 & 32 \\
Control (uninfested soil) & 1.38 & 1.31 & 0.95 & 38 & 52.4 \\
\hline
\end{tabular}

$*_{\mathrm{mg}} \mathrm{g}$ fresh leaves weight, ${ }^{*} \mathrm{mg} / \mathrm{l00g}$ fruit fresh weight 


\section{Discussion}

Farmers are interested in reducing dependence on chemical inputs. Instead, disease management should rely more on principles of Integrated Pest Management (IPM) such as sanitation, biological control, resistant cultivars, induced disease resistance. A model describing the several steps required for a successful IPM has been developed by McSpadden Gardener et al., ${ }^{20}$ where modern agriculture and horticulture must combine several objectives that seem to be almost mutually exclusive: to satisfy the nutritional needs of an increasing human population and to minimize the negative impact on the environment. In addition, beyond good agronomic and horticultural practices, growers often rely heavily on chemical fertilizers and pesticides. Such inputs to agriculture have contributed significantly to the spectacular improvements in crop productivity and quality over the past 100 years. However, the environmental pollution caused by excessive use and misuse of agrochemicals, as well as fear-mongering by some opponents of pesticides, has led to considerable changes in people's attitudes towards the use of pesticides in agriculture. Today, there are strict regulations on chemical pesticide use, and there is political pressure to remove the most hazardous chemicals from the market. Additionally, the spread of plant diseases in natural ecosystems may preclude successful application of chemicals, because of the scale to which such applications might have to be applied. Consequently, some pest management researchers have focused their efforts on developing alternative inputs to synthetic chemicals for controlling pests and diseases. Among these alternatives are those referred to as biological controls. ${ }^{21}$

Plant pathogens isolated from pepper with wilt symptoms in seven governorates in Egypt were Alternaria spp. Fusarium oxysporum, F. solani, Macrophomina phaseolina, Pythium ultimum, Rhizoctonia solani, Verticillium albo-atrum and $V$. dahliae. These fungi are known pathogens of pepper. $3,7,22-24$

Pathogenicity test of the seven isolates of both $V$. albo-atrum and $V$.dahliae indicated that all isolates of both fungi caused wilt symptoms and the Giza isolate of $V$. dahliae was the most aggressive one.

The inducer resistance chemicals (IRCs) Bion, chitosan and salicylic acid; the bacterial bioagents, i.e. Bacillus chitinosporus, $B$. megaterium, B. pumilus, B. subtilis, B. thuringiensis, Pseudomonas fluorescens and $P$. putida and compost tea resulted in significant reduction to growth of $V$. dahliae in culture. Culture filtrates from $P$. fluorescens and B. subtilis were the most efficient in reducing the linear growth of $V$. dahliae in culture.

The fungus $V$. dahliae survives in the soil and crop debris as microsclerotia. Microsclerotia enable the fungus to tolerate drastic environmental conditions and become dormant in the soil for many years in the absence of the susceptible host. Moisture and root exudates of the susceptible hosts stimulate the germination of the microsclerotia which can directly penetrate roots, colonizing the root tissue to the water-conducting xylem vesicles, which ultimately become plugged with the fungus, resulting in wilt symptoms. The fungus can be dispersed with infected transplants, machinery, vehicles, irrigation water, wind, and on particles of infested soil on farm implements. ${ }^{25}$ Infection by nematodes can result in earlier or more severe verticillium wilt of pepper.

It is well known that treatment with bio-preparations of $P$. fluorescens induce systemic resistance as the main mechanism of activity on a plant. ${ }^{26}$ P. fluorescens can produces different types of antibiotics including active 2,4-diacetyl-phloroglucinole (2,4 DAPB), which control diseases. ${ }^{26,27}$ P. fluorescens may control plant pathogens also by siderophere production, nutrient competition and the induction of systemic resistance..$^{28}$ Meena et al. ${ }^{29}$ reported that reduction in infection by the plant pathogens and increases in plant height and fresh weight of the treated plants might be due to $P$. fluorescens production of indole acetic acid as a growth regulator as well as some antibiotics, i.e. pyrrolnitrin, pyoluterin and 2,4-diacetyl phloroglucino. Protection of plants from disease by induction of systemic resistance is a new approach. This is much less harmful to the environment as compared to agrochemicals applied to control plant diseases..$^{30}$ Bacillus-based biological control agents (BCAs) have great potential in integrated pest management systems; however, relatively little work has been published on integration with other IPM management tools. ${ }^{31}$ Unfortunately, most research has focused on BCAs as alternatives to synthetic chemical fungicides or bactericides and not as part of an integrated management system.

It has been found that the use of Bion (BTH), B. subtilis and $P$. fluorescens and compost resulted in significant reduction to the severity of verticillium pepper wilt with significant increase to the fruit yield in comparison with the infested control treatment. In addition, the combination between any of the tested treatments was more efficient in reducing disease severity and increasing fruit yield than using them singly. Moreover, the combination of BTH and the two bioagents and compost was the best treatment which resulted in no apparent infection by $V$. dahliae and the highest fruit yield (not significantly different than the un-infested control). The combination of compost plus either bioagent also resulted in fruit yield that was similar to the un-infested control. Compost may provide a suitable medium for reproduction and establishment of the added bioagents and saprophytic microbes in soil. IPM is a sustainable approach to managing pests by combining biological, cultural, physical and chemical tools in a way that minimizes economic, health and environmental risks. Therefore, this work evaluates the integrated use of a material which stimulates a systemic plant resistant response (Bion), B. subtilis and P. fluorescens as BCA with compost. This protection is known to be related with the induction of the phenol pathway but the particular metabolites involved have not been determined yet. This suggests fungal growth impairment by both direct toxic effect as well as plant cell wall reinforcement. ${ }^{32}$

The mechanism of systemic acquired resistance is apparently multifaceted, likely resulting in stable broad-spectrum disease control that could be used preventatively to bolster general plant health, and resulting in long lasting protection. ${ }^{33}$

The use of organic agricultural amendments such as the composted plant debris in this respect can be advantageous both in soil fertility, recycling of agricultural residues and could provide a powerful tool for management of soil-borne plant diseases. Several composts and/or composts fortified with bioagent used as soil amendments reduced pathogens propagule density and protected plants from soilborne plant pathogens. ${ }^{4}$ Therefore, although disease management effectiveness by compost can be variable, the economic and environmental benefits derived from its use can minimize operator distrust. In addition, compost may act as a nutrient source and provide a conducive environment for the bioagents that must outcompete or inhibit plant pathogens. 
Composts have been shown to suppress several diseases in the field, although the effects have been generally smaller and more variable than in container experiments. ${ }^{34}$ The disease suppressive effect of compost generally increased with rate of application. Compost inclusion rates of at least $20 \%(\mathrm{v} / \mathrm{v})$ are normally required to consistently obtain a disease suppressive effect, particularly in peat-based media, but significant disease suppression has been found at lower inclusion rates in soil. ${ }^{4}$ Co-biotrophic bacteria re-colonized composts most rapidly $(24-48 \mathrm{~h})$ after peak heating of compost. ${ }^{35}$ The predominant biocontrol agents in this group included Bacillus, Pseudomonas and Pantoea species. In addition, Lockwood ${ }^{36}$ indicated that edaphic microorganisms stimulated by compost amendments contribute to the suppressive activity of the amended soil through four control mechanisms, i.e. antibiosis, competition, predation hyperparasitism and the induction of systemic acquired resistance in the host plant. It is supposed that Bacillus spp. could have diverse plant responses involved in synthesis and accumulation of antimicrobial phytoalexins, ${ }^{37}$ induction of hypersensitive response, ${ }^{38}$ production of defence-related proteins and siderophores, ${ }^{39,40}$ production of activated oxygen species, ${ }^{41}$ and modification of plant cell wall by deposition of callose. $^{42}$

The determinants and pathways of induced resistance stimulated by bioagents and other non-pathogenic microbes has been characterized to a limited degree. ${ }^{43,44}$ The first of these pathways, termed systemic acquired resistance (SAR), is mediated by salicylic acid (SA), a compound which is frequently produced following pathogen infection and typically leads to the expression of pathogenesis-related (PR) proteins. These PR proteins include a variety of enzymes some of which may act directly to lyze invading cells, reinforce cell wall boundaries to resist infections, or induce localized cell death A second phenotype, first referred to as induced systemic resistance (ISR, is mediated by jasmonic acid (JA) and/or ethylene, which are produced following applications of some non-pathogenic rhizobacteria. Interestingly, the SA- and JA- dependent defense pathways can be mutually antagonistic, and some bacterial pathogens take advantage of this to overcome the SAR.

Bion (BTH) is an acquired systemic resistance elicitor, which reduces many fungal diseases. ${ }^{45-47}$ This protection is known to be related to the induction of the phenol pathway but the particular metabolites involved have not been determined yet. This suggests fungal growth impairment by both direct toxic effect as well as plant cell wall reinforcement.

Organic farming is gaining worldwide acceptance and is becoming a major target for sustaining the quality of degraded soils due to the intensive use of synthetic chemicals for increasing crop production. The use of bioagents, such as bio-fertilizers or bio-pesticides is an integral part of organic cultivation, especially in vegetable cultivation. The nature of the organic amendments, the microorganisms present, the properties of the soil, and environmental conditions are key factors that can influence the populations of soil-borne plant pathogens and the crop to be protected. Using organic amendments, antagonistic microorganisms and inducer resistance chemicals in managing soil-borne pathogenic fungi introduces an alternate strategy to the prevalent use of synthetic chemicals. The mixtures of bioagents have the advantage of exercising a broad spectrum activity, enhancing the efficacy and reliability of biocontrol and ensuring greater induction of defense enzymes. Plant growth in organic amendments greatly depend on the functions performed by soil microbes particularly in the secretion of nutrient supply. The build-up of active soil microorganisms, is critically important for sustaining the productivity of soils in organic cultivation systems. Therefore, research is needed to identify and characterize locally available amendments and the impact of antagonistic organisms as related to potential of soil-borne pathogen management. The single management approach or practice such as a biological amendment or organic amendment, alone will probably not be effective in establishing disease suppression, but multiple approaches as combinations of many tools, which are coordinated together as part of an integrated management of soilborne fungi may be successful.

Biological control of root diseases is largely based upon competition between the bioagents and the pathogens. Competitive colonization of the rhizosphere by the bioagents and the use of available resources is thought to exclude many rhizosphere. ${ }^{20}$

The viability of microsclerotia of $V$. dahliae was greatly reduced by the tested bacterial bioagents. In addition, $B$. megaterium, $B$. subtilis, P. fluorescens and P. putida were the most efficient bioagents, and resulted in the complete inhibition of microsclerotia germination. In addition, few microsclerotia germinated due to the treatments with $B$. chitinosporus, B. pumilus and B. thuringiensis. The bioagents had to be added to the soil at least one week prior to transplanting pepper to affect the viability of microsclerotia.

The photosynthesis pigments including chlorophyll a, chlorophyll $\mathrm{b}$ and carotenoids as well as free and total ascorbic acid were greatly increased due to the tested treatments, i.e. BTH, both bioagents and compost in pepper plants grown in infested soil. Compost was the best treatment for reduction the impact of verticillium wilt on photosynthesis pigments as well as free and total ascorbic acid. Plants grown in un-infested soil and without any another treatment recorded the highest values of photosynthesis pigments as well as free and total ascorbic acid. The impact of the treatments on photosynthetic pigments and ascorbic acid may be due to the reduction in the activity of green plastids and vitamin-C metabolism. Similar results were obtained by Pennypacker et al. ${ }^{48}$ and Hunter et al. ${ }^{49}$ When a plant is subject to physical or physiological stress, the free ascorbic acid can be oxidized into dehydro-ascorbic acid. ${ }^{15}$

\section{Conclusion}

Strategies to manage verticillium wilt was presented that were effective for reducing inoculum density of $V$. dahliae and were not harmful to the environment or human health. The use of IRCs, and bioagents and organic compost could be used in combination as a management strategy or a part of an integrated management program. They provide eco-friendly alternatives to reduce the incidence and severity of verticillium wilt in pepper.

\section{Acknowledgement}

None.

\section{Conflict of interest}

The authors declare that there is no conflict of interest.

\section{References}

1. Akram W, Mahboob A, Javed AA. Bacillus thuringiensis strain 199 can induce systemic resistance in tomato against Fusarium wilt. Eur. Eur $J$ Microbiol Immunol (Bp). 2013;3(4): 275-280. 
2. Hanson LE. Reduction of Verticillium wilt symptoms in cotton following seed treatment with Trichoderma virens. Journal of Cotton Science. 2000;4(4):224-231.

3. Goldberg NP. Verticillium wilt. In: Pernezny KL, Roberts PD, Murphy JF, Goldberg NP, editors, Compendium of Pepper Diseases. American Phytopathological Society, St. Paul, USA; 2003:21-22.

4. Abada KA, Hassan Eman O. Effect the combination among compost, bioagents and soil solarization on management of strawberry Verticillium wilt. Inter J of Sci and Eng Res. 2017;8(2):88-99.

5. Abada KA, Attia Amany MF, El-Fiki IA. Bacterial bioagents and compost as two tools for management of eggplant Fusarium wilt. Front Environ Microbiol. 2018;4(1):1-10.

6. Martin FN, Bull CT. Biological approaches for control of root pathogens of strawberry. Phytopathology. 2002;92(12):1356-1362.

7. Abada KA, Ahmed MA. Management Fusarium wilt of sweet pepper by Bacillus strains. Amer J of Life Sci. 2014;2(6-2):19-25.

8. Ragab Mona MM, Abada KA, Abd-El-Moneim Maisa L, et al. Effect of different mixtures of some bioagents and Rhizobium phaseoli on bean damping-off under field condition. Inter $J$ of Sci and Eng Res. 2015;6(7):1009-1106.

9. Booth C. The genus Fusarium. Kew, Mycological Institute, UK Commonwealth; 1971. 237 p.

10. Domsch KH, Gams W, Anderson TH. Compendium of Soil Fungi. Academic Press, London; 1980.

11. Gilman JC. A Manual of Soil Fungi. The Iowa State College Press, Iowa, USA; $1957.450 \mathrm{p}$.

12. Dennis C, Webster J. Antagonistic properties of species groups of Trichoderma. III. Hyphal interaction. Trans Brit Mycol Soc. 1971;57(3):363-369.

13. Bejarano-Alcazar J, Blanco-López MA, Melero-Vara JM, et al. Etiology, importance, and distribution of Verticillium wilt of cotton in southern Spain. Plant Dis. 2000;80(11):1233-1238.

14. Sanogo S, El-Sebai O, Sanderson R. Severity of Verticillium wilt, plant growth, and spectral reflectance indices of chile pepper under periodic flooding and no-flooding conditions. Hort Sci. 2008;43(2):414-419.

15. Metzner H, Rau H, Senger H. Untersuchungen Zur Synchronisier barkeit einzelner Pigmentmangel-Mutanten Von Chlorella. Planta. 1965;65(2):186-194.

16. Hodges DM, Forney CF, Wismer WV. Antioxidant responses in harvested leaves of two cultivars of spinach differing in senescence rates. JASHS 2001;126(5):611-617.

17. Arnon DI. Copper enzymes in isolated chloroplasts, polyphenoloxidase in Beta vulgaris. Plant Physiol. 1949;24(1):1-15.

18. Snedecor GW, Cochran WG. Statistical Methods. 6th edition. Iowa State Univ. Press, Ames, Iowa, USA; 1967.

19. Fisher RA. Statistical Methods. 6th edition. Iowa State Univ Press, Ames, Iowa, USA; 1948.

20. McSpadden Gardener BB, Fravel DR. Biological control of plant pathogens: Research, commercialization, and application in the USA. Plant Health Progress; 2002.

21. Pal KK, Mc Spadden Gardener BB. Biological control of plant pathogens. The Plant Health Instructor; 2006. P. 1-25.

22. Attia MF, Abada KA. Control of wilt and root-rot of pepper. $7^{\text {th }}$ Cong of Phytopathol. Egypt; 1994:397-409.
23. Bhat RG, Smith RF, Koike ST. Characterization of Verticillium dahliae isolates and wilt epidemics of pepper. Plant Dis. 2003;87(7):789-797.

24. Goicoechea N. Verticillium-induced wilt in pepper: Physiologic prospective for controlling the disease. Plant PatholJ. 2006;5(2):258-265.

25. Evans G, Mc Keen CD. Influence of crops on numbers of microsclerotia of Verticillium dahliae in soil and development of wilt in south western Ontario. Can J Plant Sci. 1975;55(3):827-834.

26. Bakker PA, Pieterse CM, van Loon LC. Induced systemic resistance by fluorescent Pseudomonas spp. Phytopathology. 2007;97(2):239-243.

27. Ritika B, Utpal D. An overview of fungal and bacterial biopesticides to control plant pathogens/diseases. Afr $J$ of Microbiol. 2014;8(17):1749-1762.

28. Ramamoorthy V, Viswanathan R, Raguchander T, et al. Induction of systemic resistance by plant growth promoting rhizobacteria in crop plants against pests and diseases. Crop Protec. 2001;20(1):1-11.

29. Meena B, Marimuthu T, Velazhahan R. Role of fluorescent pseudomonas in plant growth promotion and biological control of late leaf spot of groundnut. Acta Phythopathologica et Entomologica Hungarica. 2006;41(3-4):203-212.

30. Kloepper JW, Ryu CM, Zhang S. Induced systemic resistance and promotion of plant growth by Bacillus spp. Phytopathology. 2004;94(11):1259-1266.

31. Jacobsen BJ, Zidack NK, Larson BJ. The role of Bacillus-based biological control agents in integrated pest management systems: Plant diseases. Phytopathology. 2004;94(11):1272-1275.

32. Walters D, Newton A, Lion G. Induced Resistance for Plant Defence: A Sustainable Approach to Crop Protection. Blackwell Publishing Ltd, 9600 Garsington Road, Oxford OX4 2DQ, UK; 2007. 269 p.

33. Kessmann H, Staub T, Hofmann C, et al. Induction of systemic acquired disease resistance in plants by chemicals. Annu Rev Phytopathol. 1994;32:439-459.

34. Noble R, Coventry E. Suppression of soil-borne plant diseases with composts: A review. Biocontrol Science and Technology. 2003;15(1):3-20.

35. Kwok OCH, Faby PC, Hotink HAJ, et al. Interaction between bacteria and Trichoderma harzianum in suppression of Rhizoctonia damping-off in bark compost media. Phytopathology. 1987;77:1206-1212.

36. Lockwood JL. Evolution of concepts associated with soil borne plant pathogens. Ann Rev of Phytopathol.1988;26:93-121.

37. Hammond-Kosack KE, Jones JD. Resistance gene-dependent plant defence responses. Plant Cell. 1996;8(10):1773-1791.

38. He SY, Huang HC, Collmer A. Pseudomonas syringae pv. syringae harpin Pss: a protein that is secreted via the Hrp pathway and elicits the hypersensitive response in plants. Cell. 1993;73(7):1255-1266.

39. Yu LM. Elicitins from Phytophthora and basic resistance in tobacco. Proc Natl Acad Sci U S A. 1995;92(10):4088-4094.

40. Yu X, Ai C, Xinm L, et al. The siderophore-producing bacterium, Bacillus subtilis CAS15, has a biocontrol effect on Fusarium wilt and promotes the growth of pepper. Eur J Soil Biol. 2011;47(2):138-145.

41. Baker CJ, Orlandi EW, Mock NM. Harpin, an elicitor of the hypersensitive response in tobacco caused by Erwinia amylovora, elicits active oxygen production in suspension cells. Plant Physiol. 1993;102(4):1341-1344.

42. Veit S, Wörle JM, Nürnberger T, et al. A novel protein elicitor (PaNie) from Pythium aphanidermatum induces multiple defence responses in carrot, Arabidopsis, and tobacco. Plant Physiol. 2001;127(3):832-841. 
43. Bargabus RL, Zidack NK, Sherwood JW, et al. Screening for the identification of potential biological control agents that induce systemic acquired resistance in sugar beet. Biological Control. 2004;30(2):342-350.

44. Bakker PA, Doornbos RF, Zamioudis $\mathrm{C}$, et al. Induced systemic resistance and the rhizosphere micro-biome. Plant Pathol J. 2013;29(2):136-143.

45. Oostendorp M, Kunz W, Dietrich B, et al. Induced disease resistance in plants by Chemicals. Eur J of Plant Pathol. 2001;107(1):19-28.

46. Abada KA, Attia Amany MF. Potentiality of inducer resistance chemicals and bioagents in managing lettuce downy mildew. American Journal of BioScience. 2017;5(1):4-12.
47. Zyton Marwa A, Hassan Eman O. Effect of the combination between bioagents and Benzothiadiazole (BTH) on management of Uromyces pisi the cause of pea rust. Amer J of Life Sci. 2017;5(3-1):15-23.

48. Pennypacker BW, Knievel DP, Leath KT, et al. Analysis of photosynthesis in resistant and susceptible alfalfa colonies infected with Verticillium albo-atrum. Phytopathology. 1990;80(12):1300-1306.

49. Hunter D, Foster M, McArthur JO, et al. Evaluation of the micronutrient composition of plant foods produced by organic and conventional agricultural methods. Crit Rev Food Sci Nutr. 2011;51(6):571-582. 